\title{
Scott Meyer
}

A house where 1 go alone calling A name that silence and the walls give back to me A strange house contained in my voice Inhabited by the wind $I$ invent it, my hands draw a cloud A heaven bound ship above the forests Mist that scatters and disappears As in the play of images

- Pierre Seghers

(Bachelard, 1958)

Phenomenology of a lost continent

We are all map readers, searching along the lines of our research. As sons and daughters of Carterian law, we have learned that all we seek can be revealed completely within the crosshairs of longitude and latitude. I have all due respect for the map readers of our profession and for the information they chart. But there is another land yearning for equal voice. To the map readers, its place is a matter of the plotting of coordinates. That land sought is thus assumed to have a geometrical location. Under such devices as grid and map, the land of the imaginal remains an illusive Atlantis. It is this land in which all artists seek their dwelling place and it is in this land that a dwelling place has awaited an approriate research inquiry to take up residence. My research turns toward this imaginal dwelling place.

What is requisite to our situation if we aspire toward the imaginal dwelling of Pierre Seghers' poem? How do we make of this lost continent a home, and what implication does such habitation yield within the context of art education research? The extent of my work is toward a phenomenology of the lost continent of the imaginal.

To begin, a phenomenology of the imaginal presupposes a focus on the onset of the image as it exists in an individual consciousness. When I speak of the imaginal I speak not of the imaginary, fictive nor of the product of mere fancy. I speak instead of the imaginal as Henry Corbin defines it. In the Sufism of Ibn'Arabi, the imaginal realm of Hurqalya exists as a kind of angelic interworld situated between the sensible and the intelligible; between what is purely heaven and purely terrestrial. It makes possible the situation articulated in Corbins' title, "Spiritual Body, Celestial Earth." To quote him, "It is the Earth of visions, the Earth which confers on visionary apperceptions their truth, the world through which resurrection comes to pass." (Corbin, 1977) Thus Hurqalyan dwelling grants to things and places a subject/object duality. A place or thing

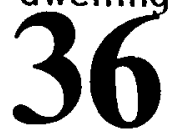


retains its physical character as part of an external world, yet this world is not purely physical. The world of Hurqalya makes it possible to emerge from measurable space without emerging from its extent. Imaginal dwelling is responsible for that apperception which yields a knowledge of a thing as a living differentiation of the Divine. It is thus that the imaginal realm comes to stand as a bridge whose invitation beckons us to dwell in Hurqalya and, in so doing, to heal the primal split between our consciousness and what is other. When this is accomplished, what is healed as well is the man-made schism between profane matter and the Divine. When we dwell in the imaginal Hurqalya, we abandon homogeneous chronological time in order to enter that qualitative time which is the history of the soul. The souls of places and things thus bared, we see all as alive in Divine differentiation and pregnant with idiosyncratic potential.

We might say then that when things are met in the person of their angel (as personal presences and differentiations of the Divine) they are permitted a life in our poetic imagination. As disciples of Divine Creation, we play forward this differentiation with out poetic consciousness and give a home to the subject/object duality which yields "an iridescent shimmering unceasingly active in its inversions" (Bachelard, 1958). It is now quite easy to make an irrefutable statement. In order to do a phenomenology of the imaginal (i.e., to bear witness to the onset of the image as it exists idiosyncratically in our consciousness), one must necessarily dwell in the imaginal. This statement has enormous implications for research, as we shall see. For now, I will say that we cannot accomplish this task by writing about the situation post facto. We must find a way to write in it.

\section{Toward Primordial Speech}

When Rainer Maria Rilke was young, he participated in an experiment which reproduced voices embeding the vibrations in waxy grooves. A needle dragged back through the grooves trembled forth a voice, the same yet different. Years later, as an adult, he wondered at his fascination over the grooves in a skull he had. He then remembered his childhood wonder over the primitive sounds made by needle and wavy grooves. This unlocked an intense image for him as he looked freshly at the world about him. If such a needle were to be run over other surfaces, would this not let loose a kind of inner voice which would represent Primal Sound?

It is the brilliance of an image which runs its needle through the grooves of past events bringing them to a reverberation within the immediacy of our place. Primal sound thus echoes of $f$ the walls of our particular idiosyncratic place (if we have cleared our place for imaginal dwelling).

It is the image which makes the past sound (not the other way around). Thus, it is an autonomous being. It is for this reason that $I$ use the word "extraphenomenological" to describe ontological events within a tradition. In the imaginal, each event has a relationship to the past but also has a relationship to a Primal Past. Thus, the particular and Universal unite in the imaginal event, giving it its own being. This phenomenology, writes Bachelard, is a phenomenology of the soul; "Poetry is a soul inaugurating form the soul inaugurates" (Bachelard, 1958). 
When "understanding" occurs in the place of tradition, it occurs within the poetic imagination as the past comes to dwell in the present event. In this light, the poetic imagination is unknowingly engaged in a hermeneutic. Note that 1 stress the word "unknowingly," and I would push Gadamer's "historical consciousness" to be more "imaginal history." In "imaginal history," the events that comprise a living tradition appear in extraphenomenological relationships and as so many iterations of the creation. Their idiosyncratic form, their particular faces, are dependent on the nature of the place being lived in. That particular place in which we dwell calls certain events to us, certain memories specific to us. As they come to us in our place, they register along the spatial axis set up by that place. Thus they come to dwell with us. Our memories reverberate within new dimensions. The echo that comes back to us is of the character of our remembered event, but poetic imagination has allowed the event to be re-membered by the present walls of our dwelling place.

\section{Poetic Language as a Mode for Inquiry}

Any mode of inquiry aspiring to understand a tradition composed of such events is necessarily an imaginative remembering and the inquiry itself an event within that tradition. My inquiry necessarily concerns itself with a place where tradition in art takes place. Specifically, I dwell in the artist's studio-classroom-community. As an artist, a teacher, and a student within this environment, I will research the onset of the image as it occurs. In so doing, I am involved with a particular place as it fosters, nurtures, and is in turn brought alive by the imaginal. I am also involved with place as it remembers images of the past for it is place which holds tradition in itself. As such, it is a phenomenology which will, in its course, call into play memories and Primordial memories as the individual plays further the tradition of the place.

The research language for such a phenomenology must mold itself to this situation. If this language is not capable of embodying this phenomenology without the usual assault gridlike inquiries inflict upon place and the image, then it is unusable. The language employed must not only invite the onset of the image and be conducive to the phenomenon of the epiphanic event of creation, it must itself be a capable medium for such an event. The research language must hold the same capacity for articulating the onset of the image as the medium of the visual artist. It must re-present the events of the place being discussed, just as does the visual art product itself.

In reality, what I aspire toward is a verbal equivalent of the artist's medium. I speak now of a language that opens itself to the imaginal as matter breaks loose from its veil and offers a phenomenon of imagery. I speak necessarily of poetic language as a legitimate mode of knowing and the only effective research tool within the context of imaginal place.

\section{Poetically Man Dwells}

It should be clear at this point how imaginal dwelling comes to bear upon the place where tradition in art takes place; the specific context of this study. With a poetic consciousness, a "youthful consciousness" as Bachelard would say, we dwell in this place. With a naive consciousness, we dwell poetically and we

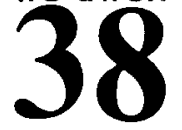


build. Heidegger refers to poetic dwelling as a kind of interative building. It is assumed that this creates a situation which I have described as extraphenomenological and thus can be built a tradition of dwelling.

The phrase "poetically man dwells" says: poetry first causes dwelling to be

dwelling. Poetry is what really lets us dwell.

But through what do we attain to a

dwelling place? Through building.

Poetic creation, which lets us dwell

is a kind of building. (Heidegger, 1971)

I must express the knittedness of this research situation. We dwell poetically in our chosen art, dreaming with clay in hand. We dwell poetically in our place as well, with the medium of words: dreaming with pen in hand. With the same poetic consciousness we invite the onset of the image in our idiosyncratic place. Both are expressions of the onset of the image and thus they reside equidistant from the event of creation, the only difference being in the charcter of material. In both cases, the place determines and is determined by the poetic event as Primordial memory stirs the particular memories of our tradition.

\section{Application}

Should the reader still have doubts at this point as to the applicability of this work to art and art education research, let me close with several comments.

With this work I hope to give the artist-art educator an adequate voice. In Gaston Bachelard, Henry Corbin, R.M. Rilke, William Blake and Kenneth Beittel as well as others, we find the cultivation of an alternative to the discursive approach which has characterized art research. It is as I have said, not my intention to disparge that discursive world but instead to offer another which is capable of still a different way of knowing. By situating the research language in the role of artist's medium, it is hoped that art and art education research will pull closer to a verbal knowledge of the nature of the subject of our field, art.

\section{References}

Bachelard, Gaston. (1958). The poetics of space. Boston: Beacon Press. Bachelard, Gaston. (1969). The poetics of reverie. Boston: Beacon Press. Be ittel, Kenneth R. (1983). National Symposium for Research in Art, Artistic Perception: Educational Philosophical Research Perspectives. "The phenomenology of the artistic image," Visual Arts Research, Vol. 9, No. 2, 25-39.

Beittel, Kenneth R. (1984). East and west of the areat tradition: The way of the potter. (Due out in the spring).

Corbin, Henry. (1969). Creative imagination and the Sufism of the Ibn'Arabi. N J: Princeton University Press.

Corbin, Henry. (1977). Spiritual Body, Celestial Earth. N J: Princeton University Press. 
Corbin, Henry. (1983). "Epistle on the state of childhood, Sohravardi," Teminos, pp. 52-76.

Gadamer, Hans Georg. (1975). Truth and method. NY: Continuum. Heidegger, Martin. (1971). Poetry, Lanquage, Thought. NY: Harper Colophon Books.

Lingis, Alphonso. "Truth and Art: Heidegger and the Temples of Constantinople." Philosophy Today.

Lobell, Mimi. (1983). "Spatial Archetypes." Revision, Vol. 6, No. 2, 69-82.

Palmer, Richard. (1969). Hermeneutics. Northwestern University Press.

Raines, Kathleen. "Science and imagination in William Blake." Temenos, No. 11 .

Rast, David Steindl. (1983). A listening heart: The art of contemplative living. NY: Crossroad.

Rilke, Rainer Maria. (1919). "Primordial sound," in Where silence reigns, 1978. NY: New Directions Publishing Corp. 